\title{
MÜŞTERİ OLARAK ÇALIŞANLAR: HASTANE ÇALIŞANLARI ÜZERİNDE BİR UYGULAMA
}

Güler YANIK 1

Vedat TANIŞ 2
Received Date (Başvuru Tarihi):

Accepted Date (Kabul Tarihi):

Published Date (Yayın Tarihi):
$15 / 07 / 2020$

$27 / 08 / 2020$

$25 / 09 / 2020$

Çalıșmada ilk yazar Sorumlu Yazar (Corresponding Author) rolündedir.

$\ddot{O} Z$

\section{Anahtar Kelimeler:}

İçel Pazarlama

İçsel Pazarlamanın Boyutları,

İş Tatmini,

Hizmet

JEL Kodlart:

M10, M51
Günümüz işletmecilik anlayışı gereği müşterinin memnuniyetinin sağlanması için çalışanlarının da memnuniyetinin sağlanması gerekmektedir. Araştırmada; içsel pazarlamanın boyutları bazında iş tatmini üzerindeki etkileri incelenmiştir. Bunun yanı sıra içsel pazarlamanın uygulamalarının çalışanların firmalarının ürün ve hizmetlerini satın almak ve tavsiye etmek konusundaki tutumları da incelenmiştir. Araştırmanın uygulaması Rize ilinde bulunan Recep Tayyip Erdoğan Üniversitesi Ĕ̆itim ve Araştırma Hastanesi çalı̧anları üzerinde gerçekleştirilmiştir. İlgili kurulumda yapılan anket uygulaması sonucu, 291 anket formu elde edilmiştir. Verilerin analizleri IBM SPSS STATICTICS 22 paket programı kullanılarak yapılmıştır. Analiz sonuçlarına göre; içsel pazarlamanın güven, güvenilirlik ve fiziksel özellikler boyutlarnın iş tatmini üzerinde; fiziksel özellikler boyutunun sunulan hizmeti alma isteği üzerinde, güven ve güvenilirlik boyutunun sunulan hizmeti tavsiye etme üzerinde pozitif yönde bir etkisi olduğu tespit edilmiştir.

Keywords: Internal Marketing $\quad \begin{gathered}\text { Dimensions of Internal } \\ \text { Marketing }\end{gathered} \quad$ Job Satisfaction $\quad$ Service

JEL Codes: $\quad$ M10 M51

\footnotetext{
${ }^{1}$ Dr. Öğr. Üyesi, Recep Tayyip Erdoğan Üniversitesi, guler.yanik@erdogan.edu.tr,

https://orcid.org/0000-0002-5228-2981

2 Recep Tayyip Erdoğan Üniversitesi, Araştırma ve Uygulama Hastanesi, Vedat.tanis@saglik.gov.tr,
} 


\section{EXTENDED ABSTRACT}

\section{EMPLOYEES AS A CUSTOMER: AN APPLICATION IN HOSPITAL EMPLOYEES}

\section{INTRODUCTION}

The happy employees for happy customers motto lead businesses to a people-oriented approach. In the realisation of the primary objectives of the business, the presence of happy customers is realised with employees who are satisfied with their business processes. The starting point of internal marketing practices is that employees examine their roles, gain awareness of customer satisfaction and adopt service orientation. These practices are considered as an essential management approach in ensuring employee motivation.

In the research, it has been investigated whether internal marketing practices affect job satisfaction. In this context, the effects of internal marketing on job satisfaction were examined. On the other hand, the willingness of employees to become customers of their institutions and to recommend their institution's services to others is also investigated.

\section{METHOD}

The main population of the research is the employees of Recep Tayyip Erdoğan University Education and Research Hospital. Questionnaire method was used for data collection. Hospital employees were applied to the hospital administration for a survey, a positive response was received, and the questionnaire forms were collected through the hospital staff department. It was aimed to create a sample by reaching $30 \%$ of the hospital staff and randomly selected subjects from the hospital staff list. Subsequently, a questionnaire was distributed to 350 hospital staff. 315 questionnaire forms were returned. 24 missing questionnaire forms were eliminated, and 291 questionnaire data were analysed in IBM SPSS STATISTICS 22 package program.

In order to measure the internal marketing variable, the "internal marketing" scale consisting of 22 items developed by Kang James and Alexandris (2002) using the Servqual service quality scale was used. The scale measures internal marketing in 5 sub-dimensions as trust, reliability, enthusiasm, empathy and physical properties. 7-item job description scale (JDI-Job Description Index) was used to measure job satisfaction. The 5-point Likert scale was used to measure all variables, consisting of the answers "absolutely disagree- absolutely agree". The respondents said, "Would you like to be treated in the hospital you work at? "Would you recommend the hospital services you work to your relatives?" questions were also addressed.

\section{FINDINGS (RESULTS)}

The internal marketing scale used in the study consists of 5 sub-dimensions: trust, reliability, enthusiasm, empathy and physical feature. However, as a result of the factor analysis, it was determined that the internal marketing scale was collected in 3 dimensions and explained $66.5 \%$ of the total variance.

In the results of the analysis, it was seen that the average of the employees to receive the services offered by their institutions and recommend them to their relatives is 3,52. According to the results of the correlation analysis, it was determined that there was a positive correlation at the level of 0,01 significance between trust and reliability, enthusiasm and empathy, physics feature dimensions of the request to receive the services of the institution to which the participants belong, and the service offered, job satisfaction and internal marketing. It was concluded that there was a positive correlation between the satisfaction of the service offered at the hospital to which the participants were affiliated, and job satisfaction, internal marketing confidence and reliability, enthusiasm and empathy, and physics feature dimensions at the level of 0,01 significance. It was observed that there was a positive correlation between job satisfaction and internal marketing confidence and reliability, enthusiasm and empathy, physics feature dimensions at the level of 0,01 significance. 
According to the regression results;

- Internal marketing's trust and reliability dimension $(\beta=, 306 \mathrm{p}<0.05)$, physical feature dimension $(\beta=, 466 \mathrm{p}<0.05)$ have a positive effect on job satisfaction,

- The physical feature dimension of internal marketing $(\beta=, 294 \mathrm{p}<0.05)$ has a positive effect on the organisation's desire to receive the service,

- It was concluded that the trust and reliability dimension of internal marketing ( $\beta=, 275 \mathrm{p}$ $<0.05$ ) had a positive effect on the service, which is the outcome of the organisation.

\section{CONCLUSION AND DISCUSSION}

Internal marketing is the implementation of marketing philosophy and practices by adapting them to organisation employees. It has been suggested that investing in this practice will provide job satisfaction and organisational commitment in employees (Kanyurhi \& Akonkwa, 2016) (Du Preez \& Bendixen, 2015). In the study, the effect of internal marketing on job satisfaction was examined. Besides, employees were asked about their potential to become an external customer of their organisation, and $70 \%$ of them answered yes. At the same rate, they stated that they would recommend the service offered by their hospitals to their relatives. This result gives the impression that hospital staff trust the work outcomes of their institutions. Because trust in an organisation is the perception of the individual that the institution he/she works for will not harm himself/herself or think about his/her interests. Organisational trust brings job satisfaction and commitment to it (Erkıllı̧ \& Aydın, 2019).

It is seen that the literature does not focus on the effects of internal marketing on job satisfaction based on its dimensions. When the effect of internal marketing sub-dimensions on job satisfaction is examined, the positive effects of trust and reliability and physical characteristics on job satisfaction are determined; no effect of enthusiasm and empathy dimensions was found. It has been observed that studies are supporting the results regarding the positive effects of trust and reliability and physical characteristics dimensions on job satisfaction. For example, the absence of Gounaris internal marketing policies and practices prevents employee satisfaction (Gounaris, 2008), and Mainardes et al. Stated that internal marketing positively affects job satisfaction (Mainardes et al., 2019). In this context, internal marketing policies and procedures should be included in management practices. Within the scope of internal marketing practices, they will feel like a valuable stakeholder of the institution by improving the working conditions of the employees and establishing physical and psychological trust elements in the working environment. This will provide a positive change in satisfaction levels and a positive attitude and behaviour towards customers.

Concerning the functioning of the bureaucracy model, the reason why the enthusiasm and empathy dimension of internal marketing does not affect job satisfaction in the research results is that the research is carried out in the public hospital; It is thought that not sharing the desired level of information, not being rewarded fairly for efforts, and efforts to empower employees may be insufficient. It is known that there are studies on the effects of the reward system on motivation and satisfaction. Papsolomou et al. (2017) suggested that as a result of internal marketing practices, the financial and psychological rewards offered by the institution can provide the employee's perception of value and motivation, and the reward system will create job satisfaction (Papasolomou et al., 2017).

It is argued that developing and maintaining a high-level employee-oriented application in an institution equates to financial and operational success (Kanyurhi \& Akonkwa, 2016). Accordingly, it is expected that some applications such as awards and training in internal marketing applications will provide job satisfaction and organisational performance increase. Therefore, managers have to understand the needs of employees (internal customers) and create a fair reward system for them, as well as establish an interactive and two-way communication system. On the other hand, internal marketing requires significant interaction between the units of the institution. It is thought that the effectiveness of internal marketing practices will increase as a result of the inclusion of human resources 
issues in marketing issues by marketing managers and the inclusion of marketing practices by human resources managers in the human resources plan.

In the study, the effects of the dimensions of internal marketing on job satisfaction were examined; The level of influence of each dimension was measured. It is believed that the results obtained will contribute to eliminating the deficiencies in management practices. The data regarding the results of the study were realised in a public hospital operating in the province of Rize. The thought that the possible effects of differences regarding the socio-cultural characteristics peculiar to the region and the nature of public institutions may have reflected on the results revealed the necessity of new fields of work. The application of the study in different sectors is essential for the validity of the results obtained.

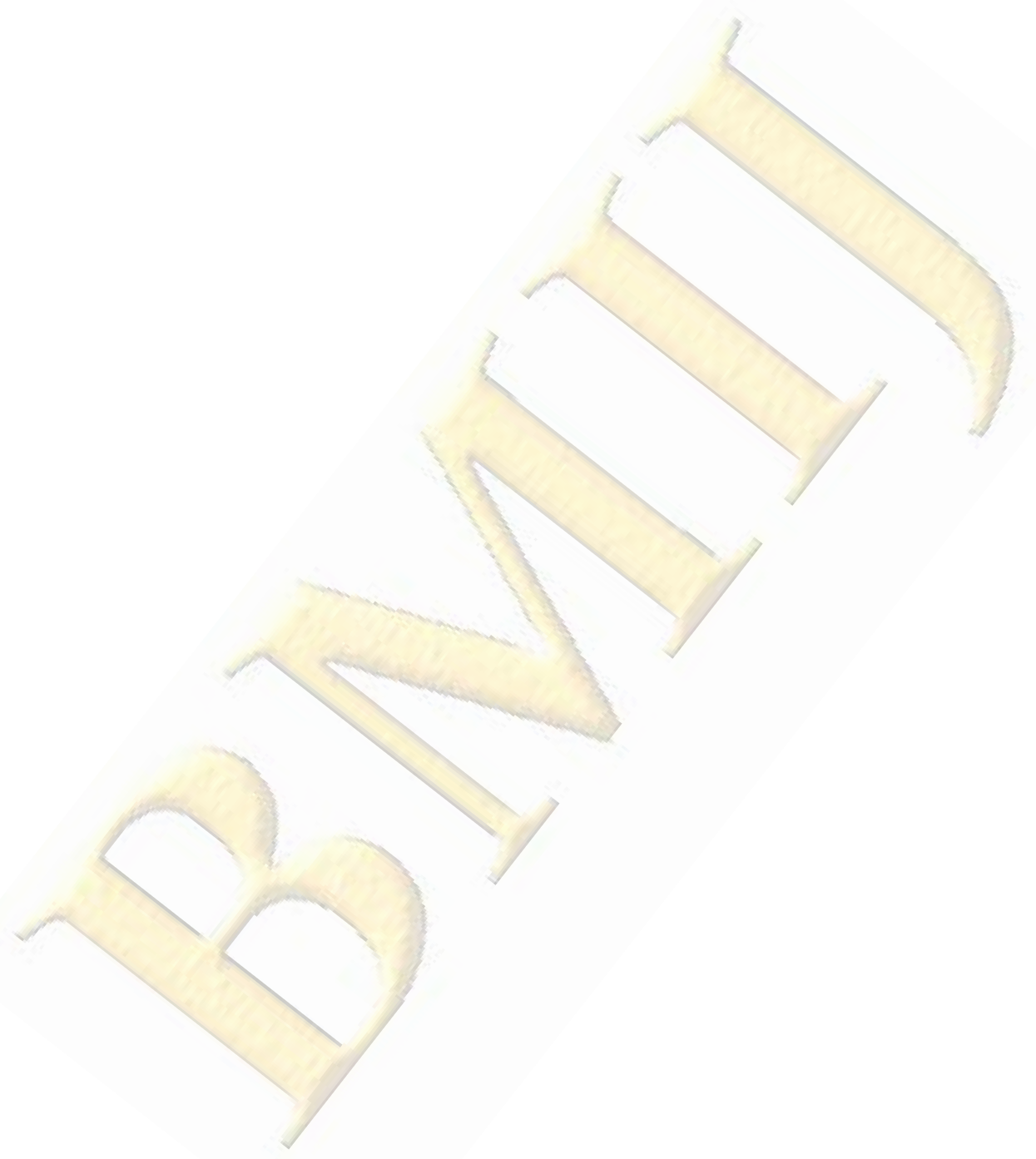




\section{GİRIŞ}

Günümüz bilgi ve iletişim çağında hızla gelişen teknolojik gelişmeler ve beraberinde getirdiği yenilikler, yoğun bir rekabet ortamı oluşturmaktadır. Mevcut rekabet ortamında kendisini işletme olarak tanımlayan organizasyonları diğerlerinden farklı kılan unsurlar bulunmaktadır. Bu unsurların en önemlisi ise işletmelerin ve işletme çalışanlarının sunduğu hizmetin kalitesinin ne olduğu, müşterilerin bu hizmet kalitesinden ne beklediği ve aynı zamanda da bu hizmeti nasıl algıladıklarıdır.

Hangi sektörde olursa olsun işletmeler kendilerini tanımlarken, asıl gayelerinin hizmet etmek olduğunu ön plana çıkarmaktadırlar. Buna göre işletmelerin hizmet verme, hizmette rekabet etme gibi önemli hususlar nasıl olmalıdır gibi birçok soru karşımıza çıkmaktadır. Öte yandan bilinen bir gerçektir ki, hizmet sunumu esnasında işletmeler en üst düzeyde donanım ve teçhizata sahip olsalar bile birincil unsur işletmenin sahip olduğu insan kaynağıdır. Araştırmanın konusu olan içsel pazarlama uygulamalarının hedefinde insan kaynakları vardır. İçsel pazarlama bir işletmenin çalışanlarını geliştirmek, eğitmek ve motive etmek, böylelikle müşterilerine sunduğu hizmetlerin kalitesini arttırmak için yapılması gereken tüm eylemleri ifade eder. Alan yazında içsel pazarlamanın uygulamalarına ilişkin olarak hizmet sektöründe ve ağırlıklı olarak finans (Awwad, Agti, 2011; Bailey vd., 2016; Berry, 1981; Caruana, Calleya, 1998; Du Preez, Bendixen, 2015; Kanyurahi, Bugandwa, 2016; Karatepe, Aga, 2016; Narteh, 2012; Papasolomou, 2006) alanında araştırma yapıldı̆̆ı göze çarpmaktadır.

Literatürde içsel pazarlama uygulamalarının iş tatmini (Tsai, Wu, 2011; Huang, Rundle, 2014; Du Preez, Bendixen, 2015; Bailey vd., 2016; Abzari, vd., 2011; Ahmed, Rafig, 2000; Ahmed, Rafig, 2003; Conduit, Mavondo, 2001) sadakat (Narteh, Odoom, 2015) işe bağl1lık (Karatepe, Aga, 2016) örgütsel bağlllık (Caruana, Calleya, 1998; Narteh, 2012; Bailey, vd., 2016; Stoffers \& Heijden, 2009) üzerindeki etkilerinin sıklıkla incelendiği görülmüştür. Örneğin içsel pazarlama uygulamaları ile iş tatmini ve organizasyonel performans arasında pozitif yönde bir korelasyon olduğu saptanmışır (Kanyurhi \& Akonkwa, 2016). Bu ilişki düzleminde bakıldığında içsel pazarlama 
uygulamalarının örgüte olan bağlılığı (Stoffers \& Heijden, 2009), ve iş tatminini arttırdığına ilişkin çalışmalara literatürde rastlanmaktadır (Abzari, vd., 2011). Bu sonuçlardan hareketle, içsel pazarlama uygulamalarını içeren insan kaynakları faaliyetlerinin çalışanların olumlu iş tutum ve davranışlarını arttıracağı, iş tatmini yüksek çalışanların işe devamsızlık gösterme ve işten ayrılma niyetlerinin azalacağı, bunun örgütsel performansı ve verimliliği de arttıracağı beklentisi doğmaktadır. Çalışmada içsel pazarlama uygulamaları ile iş tatmini arasındaki ilişkiler incelenmiştir. Bunun yanı sıra çalışanların, ihtiyaç duymaları halinde işletmelerinin ürünlerine yönelip yönelmediği ve yine işletmelerinin ürünlerini yakınlarına tavsiye edip etmediği belirlenmeye çalışılmıştır.

\section{KAVRAMSAL ÇERÇEVE}

\section{1. İçsel Pazarlama}

Parasuraman, Zeithaml ve Berry (1988) hizmet verme sürecinde hizmeti sunan personelin performansına bağlı olarak hizmet kalitesinin büyük oranda gerçekleştiğini ve "hizmet sunan personelin fiziksel mal girdisi gibi kontrol edilemeyecek bir örgütsel kaynak" olarak görülmesi gerektiği üzerinde durmuşlardır. Modern işletme faaliyetleri hem iç hem dış olmak üzere iki müşteri türü ve dolayısıyla iki pazarı dikkate alarak gerçekleştirilmek zorunda kalmıştır (Bowers \& Martin , 2007). İçsel pazarlama, pazarlama literatüründen geliştirilmiş; geleneksel pazarlama ilkelerinin, işletme çalışanlarına uygulanmaya başlamasıyla ortaya çıkmış bir kavramdır (Herington, vd., 2006) (Roberts-Lombard \& Steyn, 2008). İçsel pazarlama anlayışına göre bir kuruluşun çalışanları o kuruluşun ilk müşterileridir ve çalışanlar dış müşterinin algısını oluşturma, ilişkilendirme ve hatta etkileme becerisine sahiptir (Berry, 1981; Caruana\&Calleya, 1998; Bailey, vd. 2016) (Mainardes, vd., 2019) İşletmelerde rakipler tarafindan kopyalanmayan ve rekabet üstünlüğü yaratabilen birkaç kaynaktan biri olan çalışanlardır bu bağlamda hizmet ve müşteri odaklı bir kültür için oluşturmak özellikle hizmet işletmeleri, çalışanı odağına alan içsel pazarlama uygulamalarını benimsemeye başlamışlardır (Rafig \& Ahmed, 1993). Çalışan odaklı içsel pazarlama, organizasyonun işgücüne pazarlanması ya da tanıtılması konusu ile ilgilidir (Berry \& Parasuraman, 1992) İçsel pazarlama, 
çalışanların, kendi rollerini incelemesini, müşteriyi memnun etme bilincini ve hizmet yönelimini benimsemesini sağlayan ve motive eden bir yönetim yaklaşımı olarak değerlendirilmektedir (Cowell, 1984). İçsel pazarlamanın bir gereklilik olarak hizmet yönelimi oluşturmak, hizmet kültürü geliştirmek ve sürdürmek, yeni ürünler ve yeni pazarlama faaliyetleri sunmak için en iyi yaklaşım olduğu düşünülmektedir; ayrıca içsel pazarlamanın nihai amacı müşterilerin hizmet kalitesi ve memnuniyet algılarını arttırmak için çalışanları tatmin etmektir. Bu doğrultuda çalışan ihtiyaçlarının belirlenmesi ve karşılanması, çalışanda müşteri bilincini oluşturularak çalışanmüşteri etkileşiminin sağlanması nihayetinde müşteri memnuniyetinin arttırılması hedeflenmektedir (Quester \& Kelly, 1999) (Kelemen \& Papasolomou, 2004).

İçsel pazarlama işletmelerde yönetim fonksiyonun diğer fonksiyonlardan izole olarak ayrı faaliyet göstermesinin etkin olmadığı düşüncesine dayanmıştır. İşletmelerde farklı beceri ve donanıma sahip çalışanlar, ürün ve hizmetlerin yaratılması ve sunulmasında aktif olarak yer almak zorundadır. Yöneticiler organizasyonun tüm bölümlerindeki her çalışanın, müşteri-tedarikçi zinciri boyunca kalitenin sunulmasına dahil olmasını sağlamalıdır. Bir tedarikçi-müşteri ilişkileri ağını yönetme ve koordine etme görevi kesinlikle kolay olmayacaktır. İşletmenin tüm üyelerinin, "ne yaptı̆̆1" ile "bir sonraki müşteri" üzerindeki etkisi arasındaki bağlantıyı öngörmesi ve gözlemlemesi önemlidir (Ahmed \& Rafig, 2003) (Chang \& Chang, 2008). İçsel pazarlama, insan kaynakları ve operasyon alanları için stratejik bir araç olarak düşünülmektedir (Kanyurhi \& Akonkwa, 2016). Bu nedenle, işletme içindeki departmanlar, fonksiyonlar ve çalışanlar arasında iç ilişkileri oluşturmak ve koordine etmek, çalışan ve örgüt performansının artması için gereklidir.

Grönroos (1994) çalışmasında iç pazarlamayı tutum ve iletişim yönetimi olarak iki boyutta ele almaktadır. Tutum yönetimi işletmenin kamuoyu ile bağlarını kurmak, çalışanların müşteri ihtiyaçlarını öncelikli değerlendirmelerine ilham vermek için iç ve dış bakış açılarını bütünleştirmek olarak ifade edilmektedir. İletişim yönetimi ile yönetim etkinliğinin sağlanması, bilgi ve yetenek dağılımı, çalışanların müşteri ihtiyaçlarını karşılamaları amaçlanmaktadır (Grönroos, 1994). 
İçsel pazarlama kavramı, işletme çalışanları arasındaki ekip çalışmasının, başarılı bir iş stratejisinin geliştirilmesinde ve elde tutulmasında kilit bir faktör olduğunu vurgulamaktadır (Kale, 2007). İşletmede içsel pazarlama anlayışının varlığı, işletmenin çalışanları ile olumlu ilişkiler içinde olması gerektiği anlamına gelir. İçsel pazarlamanın bir işletmede etkin işleyebilmesi örgütün tüm üyeleri arasında anlayış, samimiyet, güven ve bağllıı ilişkisinin kurulması yani psikolojik güvenliğin sağlanması koşuluyla gerçekleşebilir (Ahmed \& Rafig, 2003). Bu psikolojik öğelerin örgütte varlığı çalışanın fizyolojik ihtiyaçları kadar gereklidir, aksi halde çalışanlarda sinizme yol açabilir. Psikolojik güvenlik çalışanların düşündükleri ve hissettiklerini paylaşma konusunda kendilerine herhangi bir tehdit gelmeyeceğine ilişkin inanca sahip olmalarıyla ilgilidir. Çalışanlar psikolojik açıdan tehdit altında olmadıklarını hissettiklerinde şeffaf ve dürüst davranırlar. Çalışanların psikolojik güvenlik ihtiyaçlarının karşılanması örgütte lider, süreç ve sistemlere güven ile sağlanabilir. İşletmede içsel pazarlama ortamının oluşturulmasını güçlendirmek için, bir işletmenin yönetimi aşağıdakilerin sürekli araştırılmasına odaklanmalıdır (Steyn, vd., 2004).

1. Çalışanların kişisel eğitimi ve gelişimi, çalışanlarla sürekli iletişim.

2. Çalışanların güçlendirilmesi ve katılımı, iç tüketici segmentasyonu.

3. Performans değerlendirme sistemleri.

4. Çalışanların kabulü ve ödüllendirilmesi ve destekleyici iş ilişkileri.

Dış müşteri memnuniyetinin iç müşteri memnuniyetinin sağlanması ile gerçekleşeceği mantığına dayanan içsel pazarlama; çalışanların işe alım, eğitim süreçlerinin başarı ile gerçekleşmesi ve çalışanların motivasyonlarının sağlanması için önemli bir araç olarak işletmelerin kullanması gereken bir uygulamadır.

\section{2. İş Tatmini}

İş tatmini kavramı 1930'larda Hoppock tarafından ortaya atılmıştır. İş tatmini çalışanların çalıştıkları iş ortamı ve edindikleri deneyimlerinden elde ettikleri ruhsal ve fiziksel tatmininden kaynaklanmaktadır. Genel olarak iş tatmini, çalışanın işiyle ilgili hissettiği duyguları ve onlara verdiği tepkiyi ifade eder (Tadeka, vd., 2005) (Shiu 
\& Yu , 2010). İş tatmini, insanların işlerini sevme ya da sevmeme derecelerinin tutumlarına yansıması olarak tanımlanmıştır (Spector, 1985).

Alan yazında iş tatminin boyutları konusunda çeşitli çalışmalar yapılmıştır. Chen ve Chiu (2005) çalışmalarında iş tatminini içsel ve dışsal tatmin olarak iki ana boyutta ele almış; iş bağımsızlığı, iş çeşitliliği, iş devamlılı̆̆ı, topluma hizmet, sorumluluk duygusu ve sosyal statünün içsel tatmin unsurları olduğunu buna karşın işletmedeki çalışma koşulları, politikalar, övgü ve takdir edilmenin dışsal tatmin unsurları olduğunu öne sürmüştür. Buna göre içsel tatmin işin kendisinden kaynaklanmakta iken dışsal tatmin işletmenin koşulları ve yönetici tutumlarından kaynaklanmaktadır (Mert, 2010). Aşan ve Erenler (2008) çalışmalarında iş tatminin boyutlarını ücret, yükselme, yöneticiler, ek imkanlar, olası ödüller, işleyiş prosedürleri, iş arkadaşları, işin kendisi ve iletişim olarak sıralamışlardır (Aşan \& Erenler, 2008). Luthans'a göre iş tatmini ücret, işin niteliği, bireyin çalışma koşulları, yönetim politikaları ve çalışma arkadaşları olmak üzere beş alt boyutta incelenmektedir.

İş tatmini sağlık sektörü de dahil olmak üzere birçok mesleki alanda yaygın olarak incelenen bir kavramdır. İş tatmini çalışan performansı (Lawler ve Proter, 1969; Locke, 1970), motivasyonu (Heller ve diğerleri ,2002; Cribbin, 1972; Davis, 1982) ve bağl1lı̆̆1 (Agho ve diğerleri, 1993; Cramer, 1996, Glisson ve diğerleri, 1998) üzerinde etkileri olan bir kavramdır (Aşan \& Erenler, 2008). İş tatmini gerçekleşmiş çalışanlar olumlu iş tutum ve davranışlarına yönelirken, iş tatmini gerçekleşmemiş ya da tatminsizlik duygusu taşıyan çalışanlarda performans düşüklüğü, devamsızlık, memnuniyetsizlik görüldüğü ve örgüte bağlılığın azaldığına ilişkin çok sayıda çalışma mevcuttur (Özpehlivan, 2018). Örneğin Nelson sağlık çalışanlarının çalıştıkları kurumlarda kalıp kalmamasının ya da gönüllü olarak işi bırakmak istemesinin, istihdam durumlarından kaynaklanan iş tatminsizliği olduğunu öne sürmüştür (Iliopoulos \& Priporas, 2011).

\section{3. İçsel Pazarlama İş Tatmini İlişkisi}

İçsel pazarlamanın temel düşüncesi, örgütün her kademesindeki çalışanları iç müşteri olarak kabul etmek ve bu bilinçle davranmaktır (Grönroos, 1984). Çalışanların 
verimilik artışındaki öneminin giderek artması, hizmet kuruluşlarının içsel pazarlamayı benimsemelerine ve dolayısıyla çalışanlarına iç müşteri olarak davranmalarına yol açmıştır (Mishra, 2010). İçsel pazarlama ve iş tatmini ilişkisi arasında ilişki eşitlik ve hizmet-kar zincir modeline dayanmaktadır. Eşitlik teorisine göre çalışanlar kendi çabaları ile elde ettikleri çıktıları karşılaştırırlar (Lings \& Greenly, 2005). Çalışanlarının gelişimine yatırım yapan kurumlar hem iş arkadaşları hem müşteriler için daha işbirlikçi, daha yardımcı olması beklenen yüksek düzeyde iş tatminine sahip çalışanlara sahip olacaklardır (Alan \& Frimpong, 2004). İçsel pazarlama ile iş tatmini ilişkisine ilişkin çalışmaların sonuçları içsel pazarlamanın iş tatmini üzerindeki etkisinin olumlu olduğu (Rafig \& Ahmed, 2000) (Conduit \& Mavondo, 2001) (Ahmed \& Rafig, 2003) (Hwang \& Chi, 2005), ve dolayısıyla örgütün performansını iyileştirdiği yönündedir (Pfeffer \& Veiga, 1999) (Nebeker \& vd., 2001).

Sağlık hizmetlerinde yapılan araştırmalarda, çalışanları içsel pazarlama yoluyla müşteri isteklerine daha duyarlı hale getiren kuruluşların hizmet kalitesini arttırdığı ve dolayısıyla müşteri memnuniyetinin daha yüksek olduğu görülmüştür. Yine sağlık kurumlarında yapılan çalışmalarda, içsel pazarlama uygulamalarının çalışanların iş tatminini olumlu yönde etkilediği sonucuna ulaşılmıştır (Chang \& Chang, 2007) (Iliopoulos \& Priporas, 2011). ABD’de bir sağlık kurumunda yapılan çalışmada içsel pazarlama bağlamında iş tatmin düzeylerindeki farklılıklar araştırılmış; katılımcı hemşirelerin iş tatminlerinde bakım kalite algısının en büyük etkiyi yarattığı görülmüştür (Peltier, vd., 2006).

Bu çalışmalardan hareketle çalışmada, içsel pazarlamanın iş tatmini üzerindeki etkisi araştırılmak istenmiş, H1 hipotezi oluşturulmuştur.

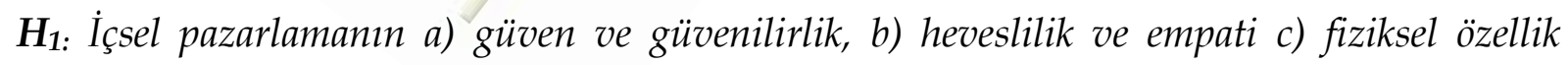
boyutları iş tatminini pozitif yönde etkiler.

İç pazarlama uygulamaları sonucu çalışanların kurumlarının iş çıktılarını olan hizmeti almak istemeleri arasındaki ilişkilere bakılmak istenmiştir ve buna göre içsel pazarlama uygulamalarının, çalışanların kurumlarının dış müşterisi olma isteği üzerindeki etkisine bakmak için H2 hipotezi oluşturulmuştur. 
$\boldsymbol{H}_{2:}$ İçsel pazarlamanın a) güven ve güvenilirlik, b) heveslilik ve empati c) fiziksel özellik boyutları sunulan hizmeti alma isteğini pozitif yönde etkiler.

Son olarak içsel pazarlama uygulamalarının çalışanların hizmet verdikleri kurumu tavsiye etmelerine etkisine bakmak için H3 hipotezi oluşturulmuştur.

$H_{3:}$ Içsel pazarlamanın a) güven ve güvenilirlik, b) heveslilik ve empati c) fiziksel özellik boyutları çalışanların hizmeti tavsiye etmesini pozitif yönde etkiler.

\section{YÖNTEM}

\section{1. Örneklem}

Araştırmanın anakütlesini Recep Tayyip Erdoğan Üniversitesi Eğitim ve Araştırma Hastanesi çalışanları oluşturmaktadır. Veri toplamada anket yöntemi kullanılmıştır. Anket uygulaması 1 Ocak 2020 tarihinden önce yapıldığı için Etik Kurul Belgesine ihtiyaç duyulmamıştır. Ancak hastane çalışanlarına anket uygulanması için hastane yönetimine başvuruda bulunulmuş, olumlu yanıt alınmış, anket formları hastane personel işleri birimi aracılığıyla toplanmıştır. Hastane çalışanlarının \%30'una ulaşılarak örneklemi oluşturmak amaçlanmış, hastanenin personel listesinden rastlantısal olarak denekler seçilmiştir. Akabinde 16 Aralık 2018 tarihinde 350 hastane çalışanına anket formu dağıtılmıştır. Yaklaşık bir buçuk ay sonrasında 315 anket formunun geri dönüşü alınmıştır. Eksik doldurulan 24 anket formu elenmiş, 291 anket formu verileri IBM SPSS STATICTICS 22 paket programında analiz edilmiştir.

Araştırmaya katılanların \%45'i yardımcı sağlık çalışanı, \%15,1'i doktor \%44,9'u idari, temizlik ve güvenlik hizmetleri çalışanlarından oluşmaktadır. Katılımcıların \%54'ü kadın, \%46'sı erkek çalışanlardır; \%40'1 20-30 yaş aralığında, \%54'ü 31-45 yaş aralığında, \%6'sı 46-60 yaş aralığındadır. Katılımcıların \%6,5 i ilköğretim, \% 19,6'sı lise \%21,3’ü önlisans, \%35,1'i lisans ve \%17,5’i lisansüstü eğitim derecesine sahiptir.

\subsection{Veri Toplama Yöntemi ve Ölçüm}

Araştırmada içsel pazarlama değişkenini ölçmek için Kang James ve Alexandris(2002) tarafından Servqual hizmet kalitesi ölçeğinden yararlanılarak geliştirilen 22 maddeden oluşan "içsel pazarlama” ölçeğinden yararlanılmıştır. Ölçek içsel pazarlamayı güven, güvenilirlik, heveslilik, empati ve fiziksel özellikler olarak 5 
alt boyutta ölçmektedir. İş tatminin ölçülmesinde 7 maddelik iş tanımlama ölçeği (JDIJob Description Index), kullanılmıştır. Tüm değişkenleri ölçmek için "kesinlikle katılmıyorum- kesinlikle katılıyorum" cevaplarından oluşan 5'li Likert ölçeği kullanılmıştır. Cevaplayıcılara "Çalıştığınız hastanede tedavi olmak ister misiniz? "Çalıştı̆̆ınız hastane hizmetlerini yakınlarınıza tavsiye eder misiniz?" soruları da yöneltilmiştir.

\section{BULGULAR}

\subsection{Analizler}

Araştırmaya konu olan değişkenlerin geçerlilik ve güvenilirlikleri sınanmış ardından boyutlarına bakılmıştır. Yapılan analiz sonucunda içsel pazarlama ölçeğinin KMO değeri 0,949; iş tatmini ölçeğinin KMO değeri 0,790 olarak bulunmuştur. KMO değerinin asgari 0,50 olması gerektiği, aksi takdirde KMO veri kümesinin faktör oluşturamayacağı ifade edilmektedir (Field, 2000). Çalışmada yer alan değişkenlerin KMO değeri 0,50'den büyüktür, dolayısıyla faktör kümelerinin oluşturulmasına elverişlidir. İçsel pazarlama değişkeninin faktör yapısını ortaya koymak için varimax dönüşümlü keşifsel faktör analizi yapılmış sonuçlar Tablo 1'de verilmiştir. 
Tablo 1. İçsel Pazarlama Ölçeğinde Yer Alan İfadelerin Faktör Yükleri

\begin{tabular}{|c|c|c|c|}
\hline \multirow[b]{2}{*}{ İfadeler } & \multicolumn{3}{|c|}{ Alt Boyutlar } \\
\hline & $\begin{array}{c}\text { Güven } \\
\text { \&Güvenilirlik }\end{array}$ & $\begin{array}{l}\text { Heveslilik } \\
\text { \&Empati }\end{array}$ & Fiziksel Özellik \\
\hline İfade 1 & ,698 & & \\
\hline İfade 2 & ,858 & & \\
\hline İfade 5 & 847 & & \\
\hline İfade 6 & 846 & & \\
\hline İfade 7 & 804 & & \\
\hline İfade 22 & ,662 & & \\
\hline İfade 8 & ,786 & & \\
\hline İfade 13 & 719 & & \\
\hline İfade 15 & ,576 & & \\
\hline İfade 18 & 604 & & \\
\hline İfade 16 & & 666 & \\
\hline İfade 17 & & 669 & \\
\hline İfade 19 & & ,606 & \\
\hline İfade 20 & & 634 & \\
\hline İfade 21 & & 634 & \\
\hline İfade 9 & & & ,721 \\
\hline İfade 10 & & & ,767 \\
\hline İfade 12 & & & ,857 \\
\hline Iffade 14 & & & 638 \\
\hline
\end{tabular}

Çalışmada kullanılan içsel pazarlama ölçeği güven, güvenilirlik, heveslilik, empati ve fiziksel özellik olmak üzere 5 alt boyuttan oluşmaktadır. Ancak yapılan faktör analizi sonucunda içsel pazarlama ölçeğinin 3 boyutta toplandığ1 ve toplam varyansın \%66,5'ini açıkladığı saptanmıştır.

Ankete katılan hastane çalışanları güven ifadelerini güvenilirlik boyutunda algılamış iki boyut Faktör 1 altında toplanmış güven ve güvenilirlik olarak yeniden adlandırılmıştır. Güven ve güvenilirlik boyutu toplam varyansın \%23,3'ünü açıklamaktadır ve alfa değeri 0, 874 hesaplanmıştır. Toplam varyansın \% 22,8'ini açıklayan Faktör 2'de heveslilik ve empati boyutları ifadelerinin toplandı ğ görülmüştür ve alfa değeri 0,915 olarak hesaplanmıştır. Faktör 3 fiziksel özellik ifadelerinden oluşmaktadır ve alfa değeri 0,881 olarak hesaplanmış, toplam varyansın \% 20,4'ünü açıklamaktadır. 
Tablo 2. Değişkenlere Ait Ortalama, Standart Sapma ve Korelasyon Analizi

\begin{tabular}{|c|c|c|c|c|c|c|c|c|}
\hline & t. & $\begin{array}{l}\text { l. } \\
\text { m. }\end{array}$ & & 2 & 3 & 4 & 5 & 6 \\
\hline $\begin{array}{l}\text { Sunulan } \\
\text { hizmetleri } \\
\text { alma isteği }\end{array}$ & 2 & 1 & & & & & & \\
\hline $\begin{array}{l}\text { Sunulan } \\
\text { hizmeti } \\
\text { tavsiye etme }\end{array}$ & 2 & 2 & $1^{* *}$ & 1 & 3 & & & \\
\hline atmini & 9 & 8 & $9^{* *}$ & $89^{* *}$ & 1 & & & \\
\hline $\begin{array}{cr}\text { Iven } & \text { ve } \\
\text { Güvenilirlik } \\
\end{array}$ & 5 & 6 & $7^{* *}$ & $43^{* *}$ & $177^{* *}$ & 1 & & \\
\hline $\begin{array}{cc}\text { veslilik } & \text { ve } \\
\text { Empati } & \\
\end{array}$ & 4 & 78 & $8^{* *}$ & $17^{* *}$ & $23^{* *}$ & $519^{* *}$ & 1 & \\
\hline $\begin{array}{l}\text { iksel } \\
\text { Özellikler }\end{array}$ & 9 & 3 & $7^{* *}$ & $09^{* *}$ & $15^{\star *}$ & $748^{* *}$ & $: 77^{* *}$ & 1 \\
\hline
\end{tabular}

Değişkenlere korelasyon analizi sonuçları Tablo 2'de verilmiştir. Analiz sonuçlarında çalışanların kurumlarının sunduğu hizmeti alma ve yakınlarına tavsiye etme ortalamasının 3,52 olduğu görülmüştür. Buna göre çalışanların kurumlarının dış müşterisi olabilecekleri yine aynı şekilde kurumlarını yakınlarına tavsiye etmek istedikleri sonucuna varılmıştır. Korelasyon analizi sonuçlarına göre katılımcıların mensubu olduğu kurumun hizmetlerini alma isteği ile sunulan hizmeti tavsiye etme, iş tatmini ve içsel pazarlamanın güven ve güvenilirlik, heveslilik ve empati, fizikler özellik boyutları arasında 0,01 anlamlılık düzeyinde pozitif korelasyon olduğu saptanmıştır. Katılımcıların mensubu olduğu hastanede sunulan hizmeti tavsiye etme ile iş tatmini, içsel pazarlamanın güven ve güvenilirlik, heveslilik ve empati, fizikler özellik boyutları arasında 0,01 anlamlılık düzeyinde pozitif korelasyon olduğu sonucuna varılmıştır. İş tatmini ile içsel pazarlamanın güven ve güvenilirlik, heveslilik ve empati, fizikler özellik boyutları arasında 0,01 anlamlılık düzeyinde pozitif korelasyon olduğu görülmüştür. 
Tablo 3. İçsel Pazarlamanın Hastane Tedavi Olma, Hastane Hizmetlerini Tavsiye Etme, İş Tatmini Üzerindeki Etkileri

\begin{tabular}{|c|c|c|c|}
\hline $\begin{array}{l}\text { Bağımsız } \\
\text { Değişkenler }\end{array}$ & Model 1 & $\begin{array}{l}\text { Sunulan } \\
\text { hizmeti } \\
\text { alma isteği } \\
\text { Model } 2\end{array}$ & $\begin{array}{c}\text { Sunulan hizmeti tavsiye etme } \\
\text { Model } 3\end{array}$ \\
\hline & $\beta \quad t$ & $\beta \quad t$ & $\beta$ \\
\hline $\begin{array}{l}\text { Güven\& } \\
\text { Güvenilirlik }\end{array}$ & $3,846^{*}$ & 701 & $2,591^{*}$ \\
\hline $\begin{array}{l}\text { Heveslilik\& } \\
\text { Empati }\end{array}$ & 691 & 1,449 & 1,248 \\
\hline $\begin{array}{l}\text { Fiziksel } \\
\text { Özellik }\end{array}$ & ,466 6,015* & $\begin{array}{c}, 294 \\
2,787^{*}\end{array}$ & ,156 1,512 \\
\hline
\end{tabular}

İçsel pazarlamanın çalışanların sundukları hizmeti alma, tavsiye etme ve iş tatmini üzerindeki etkilerini ortaya koymak için çoklu regresyon analizine başvurulmuş sonuçlar Tablo 3'te verilmiştir. İçsel pazarlamanın boyutlarının iş tatmini üzerindeki etkisi Model 1'de verilmiştir. Buna göre içsel pazarlamanın güven ve güvenilirlik boyutunun $(\beta=, 306 \mathrm{p}<0,05)$, fiziksel özellik boyutunun $(\beta=, 466 \mathrm{p}<0,05)$ iş tatmini üzerinde pozitif yönlü bir etkisi olduğu sonucuna varılmıştır. H1a ve H1c hipotezleri kabul edilmiştir.

İçsel pazarlamanın alt boyutlarının kurumun çıktısı olan hizmeti alma isteği üzerindeki etkileri Model 2' de verilmiştir. Model 2 incelendiğinde içsel pazarlamanın fiziksel özellik boyutunun $(\beta=, 294 p<0,05)$ kurumun çıtısı olan hizmeti alma isteği üzerinde pozitif bir etkisinin olduğu saptanmıştır. H2c hipotezi kabul edilmiştir. İçsel pazarlamanın alt boyutlarının kurumun çıktısı olan hizmeti tavsiye etme üzerindeki etkileri Model 3'de verilmiştir. Model 3 incelendiğinde içsel pazarlamanın güven ve güvenilirlik boyutunun $(\beta=, 275 \mathrm{p}<0,05)$ kurumun çıktısı olan hizmeti tavsiye üzerinde pozitif bir etkisinin olduğu sonucuna ulaşılmıştır. H3a hipotezi kabul edilmiştir.

\section{SONUÇ}

İçsel pazarlama, pazarlama felsefesi ve uygulamalarının örgüt çalışanlarına adapte edilerek uygulanmasıdır. Bu uygulamaya yatırım yapmanın çalışanlarda iş tatmini ve örgütsel bağlılık sağlayacağı öne sürülmektedir (Kanyurhi \& Akonkwa, 
2016) (Du Preez \& Bendixen, 2015). Araştırmada içsel pazarlamanın iş tatmini üzerindeki etkisi incelenmiş, bunun yanı sıra çalışanlara kurumlarının dış müşterisi olma potansiyelleri sorulmuş ve \%70 oranında evet cevabı alınmıştır. Yine aynı oranda hastanelerinin sunduğu hizmeti yakınlarına tavsiye edeceklerini belirtmişlerdir. $\mathrm{Bu}$ sonuç hastane çalışanlarının, kurumlarının iş çıktılarına güven duyduğu kanısı uyandırmaktadır. Zira örgüte duyulan güven, bireyin çalıştığı kurumun kendisine zarar vermeyeceğine veya menfaatini düşüneceğine ilişkin algısıdır. Örgütsel güven iş tatmini ve bağlılı̆̆ı beraberinde getirmektedir (Erkılıç \& Aydın, 2019).

Yazında içsel pazarlamanın boyutları bazında iş tatminine etkileri üzerinde durulmadığı görülmüştür. Çalışmada içsel pazarlamanın alt boyutlarının iş tatmini üzerindeki etkisi incelendiğinde, güven ve güvenilirlik, fiziksel özellik boyutlarının iş tatmini üzerinde olumlu etkileri saptanırken; heveslilik ve empati boyutunun etkisine rastlanmamıştır. Güven ve güvenilirlik ile fiziksel özellik boyutlarının iş tatmini üzerindeki olumlu etkilerine ilişkin sonuçları destekler araştırmalar olduğu görülmüştür. Örneğin Gounaris içsel pazarlama politikalarının ve uygulamalarının yokluğu, çalışanlarını tatminini engellediğini (Gounaris, 2008) ve Mainardes ve arkadaşları içsel pazarlamanın iş tatminin olumlu yönde etkilediği (Mainardes, vd., 2019) ifade etmişlerdir. Bu bağlamda içsel pazarlama politikaları ve prosedürleri yönetim uygulamalarında yer almalıdır. İçsel pazarlama uygulamaları dahilinde çalışanların çalışma koşullarının iyileştirilmesi, fiziksel ve psikolojik güven unsurlarının çalışma ortamında tesis edilmesi ile kendilerini kurumun değerli bir paydaşı olarak hissedeceklerdir. Bu durum memnuniyet seviyelerinde olumlu bir değişimi ve beraberinde müşterilere de olumlu tutum ve davranışlar sergilemelerini sağlayacaktır.

Araştırma sonuçlarında içsel pazarlamanın heveslilik ve empati boyutunun iş tatmini üzerinde etkisinin olmamasının nedeninin, araştırmanın kamu hastanesinde gerçekleştirilmesi dolayısıyla bürokrasi modelinin işleyişi ile ilgili olarak; istenilen düzeyde bilgilerin paylaşılmaması, çabaların adil şekilde ödüllendirilmemesi ve çalışanların güçlendirilmesine ilişkin çabaların yetersizliği olabileceği düşünülmektedir. Özellikle ödül sisteminin motivasyon ve tatmin üzerindeki etkilerine ilişkin çalışmaların da olduğu bilinmektedir. Papsolomou ve arkadaşları 
(2017) içsel pazarlama uygulamalarının sonucu kurumun sunduğu finansal ve psikolojik ödüllerle çalışanda değer algısı ve motivasyon sağlayabileceğini, ödül sisteminin iş tatmini oluşturacağını öne sürmüşlerdir (Papasolomou, vd., 2017).

Bir kurumda yüksek düzeyde çalışan odaklı uygulama geliştirmenin ve sürdürmenin finansal ve operasyonel başarıya eşit olduğu öne sürülmektedir (Kanyurhi \& Akonkwa, 2016). Buna göre içsel pazarlama uygulamalarında ödül ve eğitim gibi bazı uygulamaların iş tatmini ve örgütsel performans artışı sağlayacağı beklenmektedir. Bu nedenle yöneticiler, çalışanların(iç müşterilerin) ihtiyaçlarını anlamak ve onlara adil bir ödül sistemi oluşturmak, bunun yanı sıra etkileşimli ve iki yönlü iletişim sistemi kurmak zorundadır. Diğer taraftan içsel pazarlama kurumun birimleri arasındaki etkileşimi etkin gerçekleşmesini gerektirmektedir. Pazarlama yöneticilerinin insan kaynakları konularını pazarlama konularına dahil etmeleri ve insan kaynakları yöneticilerinin pazarlama uygulamalarını insan kaynakları planına dahil etmeleri sonucunda içsel pazarlama uygulamalarının etkililiğini artacağı düşünülmektedir.

Çalışmada içsel pazarlamanın boyutlarının iş tatmini üzerindeki etkileri incelenmiş; her bir boyutun hangi düzeyde iş tatminine etkisi olduğu ölçülmüştür. Elde edilen sonuçların yönetim uygulamalarındaki eksiklikleri gidermesi hususunda katkı sağlayacağı düşünülmektedir. Çalışma elde edilen sonuçlara ilişkin veriler Rize ilinde faaliyette bulunan bir kamu hastanesinde gerçekleşmiştir. Bulunulan yöreye has sosyo-kültürel özellikler ve kamu kurumlarının doğasına ilişkin farklılıkların olası etkilerinin sonuçlara yansımış olabileceği düşüncesi beraberinde yeni çalışma sahalarının gerekliliğini ortaya çıkarmıştır. Çalışmanın farklı sektörlerde uygulanması elde edilen sonuçların geçerliliği için önem teşkil etmektedir. 


\section{KAYNAKÇA}

Abzari, M., Ghorbani, H. \& Madani, F. (2011). The effect of internal marketing on organisational commitment from market-orientation viewpoint in hotel industry in Iran. International Journal of Marketing Studies , 3(1), 147-155.

Ahmed, P. K. \& Rafig, M. (2003). Internal marketing issues and challenges. European Journal of Marketing, 1177-1186.

Alan, W. \& Frimpong, J. (2004). A conceptualisation of the satisfaction-service performance. Journal of Services Marketing, 18(6), 471-481.

Aşan, Ö. \& Erenler, E. (2008). İş Tatmini ve Yaşam Tatmini İlişkisi. Süleyman Demirel Üniversitesi İktisadi ve İdari Bilimler Fakültesi Dergisi , 13(2), 203-216.

Berry, L. \& Parasuraman, A. (1992). Services marketing startsfrom within. Marketing M, 7(1), 25-34.

Bowers, M. R. \& Martin, C. L. (2007). Trading places redux: employees as customers, customers as employees. Journal of Services Marketing, 21(2), 88-98.

Chang, C. \& Chang, H.(2007). Effects of internal marketing on nurse job satisfaction and organisational commitment: example of medical centers in Southern Taiwan. The Journal of Nursing Research, 15(4), 265-274.

Chang, C. S. \& Chang, H. C. (2008). Perceptions of internal marketing and organisational commitment by nurses. Journal of Advanced Nursing, 65(1), 92-100.

Conduit, J. \& Mavondo, F. T. (2001). How critical is internal customer orientation to market orientation. Journal of Business Research, 51(1), 11-24.

Cowell, D. (1984). The Marketing of Services. London: Heinemann.

Du Preez, R. \& Bendixen, M. (2015). The impact of internal brand management on employee job satisfaction, brand commitment and intention to stay. International Journal of Bank Marketing, 33(1), 7891.

Erkılıç, E. \& Aydın, E. (2019). Otantik Liderliğin Örgütsel Güven Üzerindeki Etkisi: Konaklama İşletmeleri Çalışanları Üzerine Bir Araştırma. BMJI, 7(5), 2427-2446.

Field, A. (2000). Discovering Statistics using SPSS for Windows. Sage p. London-Thousand Oaks- New Delhi: Sage Publications.

Gounaris, S. (2008). Antecedents of internal marketing practice: some preliminary empirical evidence. International Journal of Service Industry Management, 19(3), 400-434.

Grönroos, C. (1984). A service quality model and its marketing implications. European Journal of Marketing, 18(4), 36-44.

Grönroos, C. (1994). From scientific management to service management. International Journal of Service Industry Management, 5(2), 5-20.

Herington, C., Johnson, L. \& Scott D. (2006). Internal relationships- Linking practitioner literature and relationship marketing theory. European Business Review, 18(5), 364-381.

Hwang, I. S. \& Chi, D. (2005). Relationships among Internal Marketing, Employee Job Satisfaction and International Hotel Performance: An Empirical Study. International Journal of Management, 22(2), 285293. 
Iliopoulos, E. \& Priporas, C.-V. (2011). The effect of internal marketing on job satisfaction in health services: A pilot study in public hospitals in Northern Greece. BMC Health Services Research, Cilt 11.

Iliopulos, E. \& Priporas, C.-V. (2011). The effect of internal marketing on job satisfaction in health services: a pilot study in public hospitals in Northern Greece. BMC Health Services Research, 11(261).

Kale, S. (2007). Internal Marketing: An Antidote for Macau's Labor Shortage. UNLV Gaming Research \& Review Journal, 11(1), 1-11.

Kanyurhi, E. B. \& Akonkwa, D. B. (2016). Internal marketing, employee job satisfaction, and perceived organisational performance in microfinance institutions. International Journal of Bank Marketing, 34(5), 773-796.

Karavardar, G. (2012). Çalışan İlişkileri ve Bilgi Paylaşımı: Bankacılık Sektöründe Bir Uygulama. Çankırı Karatekin Üniversitesi İIBF Dergisi, 2(1), 145-156.

Kelemen, M. \& Papasolomou, D. (2004). Can culture be changed? a study of internal marketing.. The Service Industries Journal, 24(5), 121-135.

Keser, A. (2006). Çağrı Merkezi Çalışanlarında İş Yükü Düzeyi ile İş Doyumu İlişkisinin Araştırılması. Kocaeli Üniversitesi Sosyal Bilimler Enstitüsü Dergisi, Issue 100-119, p. 11.

Lings, I. \& Greenly, G. (2005). Measuring internal market orientation. Journal of Service Research, 7(3), 290-305.

Mainardes, E., Rodriges, L. S. \& Teixeira, A. (2019). Effects of internal marketing on job satisfaction in the banking sector. International Journal of Bank Marketing , 37(5), 1313-1333 .

Mert, İ. (2010). İş Tatmini Alt Boyutlarının Örgütsel Vatandaşlık Davranışı Üzerindeki Etkisi: Yöneticiler Üzerine Bir Araştırma. Savunma Bilimleri Dergisi, 9(2), 117-143.

Mishra, S. (2010). Internal marketing - A tool to harness employees' power in service organisations in India. International Journal of Business and Management, 5(1), 185-193.

Nebeker, D. Busso, L., Werenfels, P.D., Diallo, H., Czekajewski, A. and Ferdman, B.(2001). Airline station performance as a function of employee satisfaction. Journal of Quality Management , 6(1), 29-45.

Özpehlivan, M.(2018). İş Tatmini: Kavramsal Gelişimi, Bireysel ve Örgütsel Etkileri, Yararları ve Sonuçları. Kırklareli Üniversitesi Sosyal Bilimler Dergisi , 2(2), 43-70.

Papasolomou, I., Kitchen, P. \& Christofi, M. (2017). Internal marketing under disguise: misplaced application. Journal of Customer Behaviour, 16(1), 5-18.

Peltier, J., Pointer, L. \& Schibrowsky, J.(2006). Internal Marketing and the Antecedents of Nurse Satisfaction and Loyalty. Health Marketing Quarterly, 23(4), 75-108.

Pfeffer, J. \& Veiga, J. (1999). Putting People First for Organisational Success. Academy of Management Perspectives, 13(2), 37-48.

Quester, P. \& Kelly, A. (1999). Internal marketing practices in the Australian financial sector: an exploratory study. Journal of Applied Management Studies, 8(2), 217-229.

Rafig, M. \& Ahmed, P. (1993). The scope of internal marketing: defining the boundary between marketing and human resource management. Journal of Marketing Management, Cilt 9, 219-232.

Rafig, M. \& Ahmed, P. (2000). Advances in the internal marketing concept: definition, synthesis and extension. Journal of Services Marketing, 14(6), 449-462. 
Roberts-Lombard, M. \& Steyn, T. (2008). The Relationship marketing practices og travel agencies in the Western Cape Province. S.Afr.J.Bus. Manage., 39(4), 15-26.

Shiu, Y.-M. \& Yu , T.-W. (2010). Internal marketing, organisational culture, job satisfaction, and organisational performance in non-life insurance. Service Industries Journal, 30(6), 793-809.

Spector, P. (1985). Measurement of human service staff satisfaction: Development of the job satisfaction survey. American Journal of Community Psychology, 13(6), 693-713.

Steyn , T., Ellis , S. \& Musika, F. (2004). Implementing relationship marketing the role of internal and external customer orientation. Brussels, EIASM.

Stoffers, J. \& Heijden, B. (2009). Towards an HRM model predicting organisational performance by enhancing innovative work behaviour: a study among Dutch SMEs in the province of Limburg. Business Leadership Review, 6(4), 1-13.

Tadeka, F., Ibaraki, N, Yokoyama, E., Miyake,T., Ohida T. (2005). The relationship of job type to burnout in social workers at social welfare offices. Journal of Occupational Health, 47(2), 119-125. 